\title{
Early Functions of Poliovirus \\ I. The Inhibition of Cellular Protein Synthesis in HeLa Cells after Infection with Active and Inactivated Poliovirus
}

\author{
Klaus Koschel, Helmut TäUber, and Eberhard Wecker \\ Institut für Virologie der Universität Würzburg \\ (Z. Naturforsch. 26 b, 798-803 [1971] ; received March 3, 1971, revised May 10, 1971)
}

\begin{abstract}
Evidence is presented that the genome of the infecting poliovirus must be intact in order to achieve inhibition of cellular protein synthesis. Viral particles with a single lethal hit by treatment with hydroxylamine no longer participate in the inhibitory action of the virus. De novo protein synthesis is required for the inhibition to occur. The synthesis of cellular m-RNA is not necessary.
\end{abstract}

The replication of poliovirus is likely to depend upon the expression of all of the genetic information present in the viral RNA. One can, however, observe in infected cells several events that take place prior to virus maturation. One of them is the inhibition of cellular protein synthesis (shut-off phenomenon) ${ }^{1-4}$, another is the replication of viral RNA. Both these processes may be regarded as the result of viral gene expression, e.g. the function of newly synthesized virus specific proteins. If the corresponding genes could be expressed independently of others they might be able to do so even if some different parts of the viral genome were rendered non-functional. Several authors have studied the shut-off phenomenon by polio viruses ${ }^{5-8}$ and MARTIN and KERR ${ }^{9}$ have published an extensive discussion of this subject. MARTIN and KERR came to the conclusion that the results so far known are far from being conclusive or that they are even contradictory.

We have investigated the question whether the shut-off phenomenon and the replication of poliovirus RNA, can be brought about by viruses that are inactivated by treatment with hydroxylamine.

In the present first communication two aspects are being studied

Reprint requests to Dr. K. Kosches, Institut für Virologie der Universität Würzburg, D-8700 Würzburg, Versbacher Landstr. 7.

1 R. Bablanian, H. J. Eggers, and I. Tamm, Virology 26, 100 [1965].

2 J. J. Holland, J. molecular Biol. 8, 574 [1964].

3 N. P. Salzman, R. Z. Lockart, and E. D. Sebring, Virology 9, 244 [1959].

4 E. Zimmerman, M. Heeter, and J. E. Darnell, Virology 19, 400 [1963].
1. Does the shut-off phenomenon require de-novo synthesis of proteins before it develops?

2. Can virus particles rendered non-infectious by treatment with hydroxylamine (or UV-irradiation) still evoke the shut-off phenomenon?

\section{Materials and Methods}

\section{Cells and Virus}

HeLa S 3-cells (Flow Laboratories Ltd., Irvine, Scotland) were grown in Roux-flasks. Cells were then transferred into GBI-spinner medium (Eagle) containing $5 \%$ calf serum 24 hours before starting the experiments and kept in suspension by a magnetic stirrer: the cells were grown to about $1 \times 10^{6} \mathrm{cells} / \mathrm{ml}$.

Poliovirus type I (Mahoney) was isolated 22 hours p. i. from lysates of infected HeLa S 3-cells:

Pooled lysates were centrifuged at $1000 \mathrm{~g}$ for $10 \mathrm{~min}$ at $0^{\circ}$ to remove cell debris. The supernate was filtered through a Sartorius membrane filter $(0.45 \mu$; Sartorius, Göttingen, Germany) and then centrifuged in a Beckman L-2 preparative centrifuge (rotor 30, 3 hours, $30.000 \mathrm{rpm}, 4{ }^{\circ} \mathrm{C}$ ). A 150 fold enrichment of the virus was thus achieved. The pellet was treated with PBS in an ultrasonifier (Bronson Model 125, 15 sec, grate 1) and small portions of the resulting virus preparation were stored at $-70^{\circ} \mathrm{C}$ until use.

Before each experiment an aliquot of the virus suspension was titrated on HeLa S 3-cells by means of the monolayer plaquest according to DuLBECCO ${ }^{10}$

5 S. Penman, K. Scherrer, Y. Becker, and J. E. Darnell, Proc. nat. Acad. Sci. USA 49, 654 [1963].

6 S. Penman and D. F. Summers, Virology 27, 614 [1965].

7 D. F. Summers and J. V. Maizel, Virology 31, 550 [1967].

8 M. Willems and S. Penman, Virology 30, 355 [1966].

9 E. M. MARTIN and I. M. KERR, in: The molecular biology of viruses, $18^{\text {th }}$ Symposium of the Soc. for General Microbiology (Edts. L. V. CRA WFORD and M. G. P. STOKER) p. 15, Cambridge Univ. Press, Cambridge 1968.

10 R. Dulbecco, Proc. nat. Acad. Sci. USA 38, 747 [1952]. 
(petridishes $60 \times 15 \mathrm{~mm}$, Greiner \& Söhne, Nürtingen, Germany). To determine the titer of a specific suspension as accurately as possible, $10-15$ plates of an appropriate dilution giving $40-80$ plaques/plate were counted. The mean titer was calculated with a standard deviation of 5-10 percent. Since the determination of cell numbers, especially when they are small, is rather inaccurate, the multiplicities used may be subject to a higher error. Internal controls were therefore used in each experiment using aliquots of the respective virus and cell suspensions.

\section{Inactivation of the virus by hydroxylamine}

Polio virus preparations were inactivated at $30{ }^{\circ} \mathrm{C}$ with $0.1 \mathrm{M}$ or $0.2 \mathrm{M}$ hydroxylamine-hydrochloride solutions at $\mathrm{pH}$ 6.8. Inactivation was arrested by diluting the samples tenfold in ice-could PBS, containing $0.05 \%$ BSA and by immersion in an ice bath. The samples were immediately dialysed (Viscing dialysis bags, $\varnothing$ $20 \mathrm{~mm}$ ) in the cold against PBS. The dialysis buffer was changed 3 times within the first 3 hours; dialysis was then continued over night. The degree of inactivation was determined in the plaque assay as described above.

\section{Infection of cells and general experimental design}

HeLa S 3-cells from a suspension culture were harvested $(400 \mathrm{~g}, 10 \mathrm{~min})$ and washed once with GBIspinner medium without serum. $10 \mathrm{ml}$ aliquots containing a total of $10^{7}$ cells were prepared. Each of the aliquots was infected with virus at the appropriate multiplicity, stirred for $40 \mathrm{~min}$ at $37^{\circ} \mathrm{C}$ and adjusted to $100 \mathrm{ml}$ with GBI-spinner medium containing $5 \%$ calf serum.

At the times given in the various experiments $10 \mathrm{ml}$ samples $\left(\triangleq 1 \times 10^{6}\right.$ cells $)$ were withdrawn and incubated for $10 \mathrm{~min}$ with $1 \mathrm{ml}$ GBI-spinner medium containing $0.7 \mu \mathrm{Ci}{ }^{14} \mathrm{C}$-protein hydrolysate $(54 \mathrm{mCi} / \mathrm{m}$ Atom C, Radiochemical Center, Amersham, England). The pulse was terminated by the addition of frozen PBS and immediate centrifugation $(1000 \mathrm{~g}, 5 \mathrm{~min})$ in the cold. The cells were resuspended and washed 3 times in PBS. The final cell sediment was precipitated with $3 \mathrm{ml}$ of $5 \%$ trichloro acetic acid (TCA). Further procedures are given below. Whenever changes in the above technique were necessary they are indicated in the legends to the Figures.

\section{Measurement of Radioactivity}

TCA precipitates were filtered through Sartorius membrane filters $(0.45 \mu)$ and the precipitates washed on the filter with $5 \%$ TCA $(3 \times 2 \mathrm{ml})$ and $0.1 \mathrm{~N} \mathrm{HCl}$ $(1 \times 2 \mathrm{ml})$. The filters were dried and radioactivity retained was determined in toluene/POPOP/PPO in a Packard liquid scintillation spectrometer.

11 D. Baltimore, R. M. Franklin, and J. Callender, Biochim. biophysica Acta [Amsterdam] 76, 425 [1963].

12 R. M. Franklin and D. Baltimore, Cold Spring Harbor Sympos. 27, 175 [1962].

\section{Results}

\section{Inhibitory Effect and Protein Synthesis}

In the case of picornaviruses, the inhibitory effect on cellular protein synthesis can be prevented when puromycin or $p$-fluorophenylalanine at low concentrations are added soon after infection ${ }^{11-13}$.

We have used another experimental approach.

Actidione (1 mM) inhibits $98 \%$ of protein synthesis almost immediately after its addition to $\mathrm{HeLa}$ cells ${ }^{14}$. The inhibition is reversible upon removal of the inhibitor. The following experiment is thus

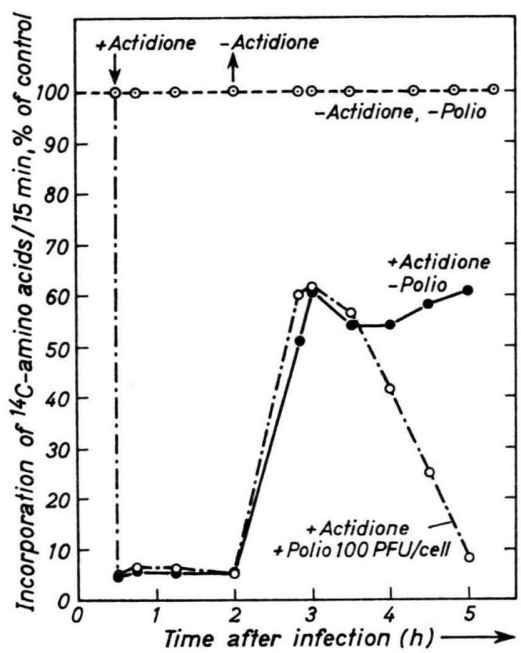

Fig. 1. Influence of actidione on the development of virus induced inhibition of cellular protein synthesis. Three identical cell cultures were kept in suspension in $10 \mathrm{ml}$ of spinner medium without serum (materials and methods). Sets 1 and 2 were left uninfected, set 3 was inoculated with $100 \mathrm{PFU}$ of poliovirus per cell. After 30 min set 1 was given $80 \mathrm{ml}$ of spinner medium containing $5 \%$ calf serum. Set 2 and the infected set 3 received the same amount of medium containing actidione at a concentration of $1.07 \mathrm{~mm}$. At the times indicated in the Fig., $5 \mathrm{ml}$ samples were withdrawn, incubated with ${ }^{14} \mathrm{C}$-amino acids for $10 \mathrm{~min}$ and further processed as described (mat. and meth.). The concentration of actidione was kept at $1.07 \mathrm{~mm}$ during the pulses of set 2 and 3 . Two hours after infection all three sets were harvested, washed twice with $100 \mathrm{ml}$ of medium without serum and adjusted to the original cell concentration with $80 \mathrm{ml}$ of spinner medium containing $5 \%$ calf serum. Further samples were taken, but from all three sets they were pulsed with ${ }^{14} \mathrm{C}$-amino acids without actidione. $0--0$ uninfected, no actidione (set 1 ), ---0 uninfected, plus actidione (set 2), $0-\cdot-\cdot 0$ infected, plus actidione (set 3 ). (Sets treated with actidione do not reach the values of the control, probably due to incomplete removal of actidione.)

13 D. W. Ver WOERd and P. Hausen, Virology 21, 628 [1963]. 14 D. Baltimore, M. Girard, and J. E. Darnell, Virology 29, 179 [1966]. 


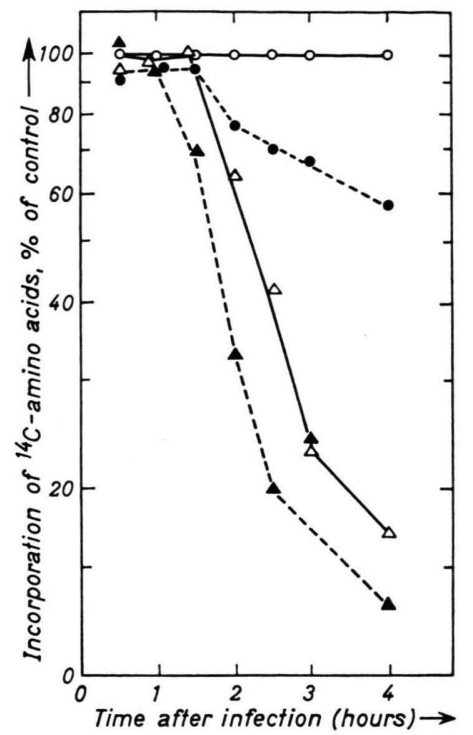

Fig. 2. The influence of actinomycin $D$ on the inhibition of cellular protein synthesis by poliovirus infection. The antibiotic was added at the beginning of infection. $\mathrm{O}-\mathrm{O}$ uninfected control without actinomycin D $(100 \%)$. - - uninfected control with actinomycin D $(5 \mu \mathrm{g} / \mathrm{ml})$. $\triangle \longrightarrow \triangle$ in fected cells (20 PFU per cell) without actinomycin D. $\boldsymbol{\Delta}-\boldsymbol{\Delta}$ infected cells (20 PFU per cell) with actinomycin D $(5 \mu \mathrm{g} / \mathrm{ml})$.

feasible: Of two identical suspension cultures of HeLa S 3-cells one is infected with poliovirus (100 $\mathrm{PFU} /$ cell) (sample 1), the other (sample 2) serves as uninfected control. In both samples protein synthesis is inhibited by actidione $30 \mathrm{~min}$ after infection of sample 1. Two hours after infection the inhibitor is removed from both samples by washing the cells twice in fresh medium. The cells are further incubated for 3 hours. Aliquots from both samples are taken at the indicated times and short pulses with ${ }^{14} \mathrm{C}$-amino acids yield the data given in Fig. 1. One can conclude that no inhibitor was produced during the presence of actidione since, after removal of actidione, uninfected controls and infected cells rise to the same level of protein synthesis. However, while protein synthesis in the uninfected control remains constant, infected cells show a normal development of the shut-off phenomenon during the ensuing $1^{1 / 2}$ hours (see also Fig. 2). This denotes that for inhibitions of cellular protein synthesis de novo viral protein synthesis is directly or indirectly required.

\section{Actinomycin and inhibitor function}

The question whether or not cellular m-RNA synthesis is necessary for the shut-off of cellular pro- tein synthesis after poliovirus infection has been investigated by Holland and PETERson ${ }^{15}$ by adding actinomycin D before infection. They found that actinomycin $\mathrm{D}$ does not prevent the development of the inhibitor function but instead leads to its slight enhancement. The observations were fully confirmed with our system (Fig. 2).

The conclusion seems to be justified that the information necessary for manifestation of the inhibitory function is probably coded for by the virus, because prevention of cellular m-RNA-synthesis does not interfere with it. To further investigate the question whether or not virus-derived information is essential for development of the inhibitor function, experiments were carried out with inactivated poliovirus preparations.

\section{Inactivation of virus and inhibitor function}

Poliovirus preparations which have been $99,9 \%$ inactivated by UV-light have lost all ability to shutoff cellular protein synthesis ${ }^{6}$. The same behaviour is exhibited by poliovirus particles presensitized by proflavine and then light inactivated ${ }^{2}$. In these experiments, the virus particles are multiply hit and many of the hits will be lethal. Until now the question has remained unanswered whether the specific function of the genome which leads to the shut-off phenomenon is as sensitive to inactivation as is the sum of all other functions of the viral genome, that is "infectivity". In other words, some viral gene functions may still be performed, even though the infectivity has been lost. We tried to determine, whether or not a virus particle with a single lethal hit in its genome can still contribute to the inhibitory effect on cellular protein synthesis.

The question can be answered under the following three conditions:

a) A demonstrable correlation between multiplicity of infection and the degree of the shut-off phenomenon.

b) Inactivation of the virus must not alter the protein coat and its function, i. e. adsorption and penetration.

c) A quantitative evaluation has to be possible between the number of lethal hits in individual viral genomes and the relative number within a population of viruses with $1,2, \ldots n$ hits in their genome.

15 J. J. Holland and J. A. Peterson, J. molecular Biol. 8, 556 [1964]. 


\section{Inhibition and Multiplicity of Infection}

The dependence of the inhibitor function on the multiplicity of infection was studied by using constant cell numbers and increasing input multiplicities. At various times after infection aliquots were taken from the individual infected cultures and the incorporation of ${ }^{14} \mathrm{C}$-amino acids was determined in a pulse experiment. The data are given in Fig. 3 relative to an uninfected control.

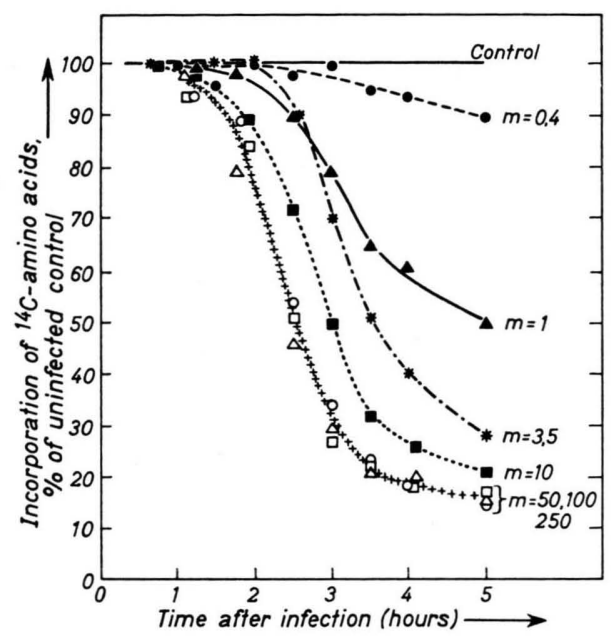

Fig. 3. Inhibition of cellular protein synthesis and multiplicity of infection. The values of multiplicities $(m)$ are shown in the diagram.

Both the time necessary for the inhibition to become first detectable and the degree of inhibition at a specific time are highly dependent on the multiplicity of infection. However, a saturation value is reached at a multiplicity of about $20 \mathrm{PFU} /$ cell. Higher multiplicities neither lead to increased inhibition nor is inhibition detectable at an earlier time. Even when infection is synchronous (e.g. at 100 PFU/cell) the inhibition can only be measured 1 1.25 hours post infection under our conditions. This suggests a quantitative effect, that is, a certain amount of inhibitor has to be synthesized in order to obtain a measurable effect.

Once the dependence of the effect on multiplicity is established, a possible participation of inactivated viruses in the events leading to the inhibition of cellular protein synthesis can be studied.

16 H. SChuster, J. molecular Biol. 3, 447 [1961].

17 R. M. Franklin and E. Wecker, Nature [London] 184, 343 [1959].

\section{Inactivation}

Treatment of poliovirus particles with hydroxylamine, under the conditions chosen, leads to a preferential damage of the viral RNA-bases cytosine and, much less frequently, uracil ${ }^{16}$. The treatment seems to satisfactorily answer condition b). Changes in the protein coat are not to be expected for chemical reasons. In addition, viral neuraminidase does not show a loss of enzymatic activity after treatment with hydroxylamine ${ }^{17-19}$. Furthermore, the kinetics of hydroxylamine inactivation are the same for intact ME-virus and its isolated infectious RNA, suggesting that only the RNA is attacked by the chemical agent but not the virus protein ${ }^{17}$. As in the case of other RNA-viruses, inactivation of poliovirus shows pseudomonomolecular first order kinetics ${ }^{17-19}$. This fact is shown in Fig. 4 for 0.1 and $0.2 \mathrm{M}$ hydroxylamine at $30^{\circ} \mathrm{C}$. The kinetics of inactivation is linear implying that one lethal hit in the genome leads to the loss of infectivity. Sublethal hits cannot be detected by the plaque technique. Lethal hits, however, are distributed statistically and independently of sublethal hits already present. Also, the plaque assay does not distinguish between virus particles which received one single lethal hit and those which received several lethal hits.

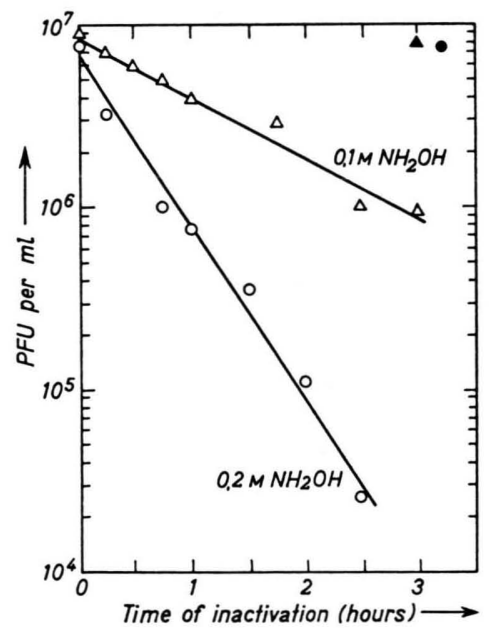

Fig. 4. The kinetics of inactivation of poliovirus by hydroxylamine. $\triangle-\triangle 0.1 \mathrm{M}$ hydroxylamine, $\mathrm{pH} 6.8 ; 30^{\circ} \mathrm{C}$. $\circ-00.2 \mathrm{M}$ hydroxylamine, $\mathrm{pH} 6.8 ; 30^{\circ} \mathrm{C}$. $\Delta$ and $\bullet$ incubation of the virus in buffer without hydroxylamine at $30^{\circ} \mathrm{C}$.

18 W. RotT and W. SchÄFER, Z. Naturforsch. 17 b, 861 [1963].

19 W. SCHÄFER and W. RoTT, Z. Hygiene 148, 256 [1962]. 
The plaque assay determines the number of infectious particle before inactivation and those surviving after a time of inactivation. By means of the Poisson distribution one may determine the number of particles with $1,2,3, \ldots n$ lethal hits in the virus population ${ }^{20}$ for any survival.

Fig. 5 shows the graph of the function

$$
\sum_{n=0}^{n}\left(\mathrm{P}_{n}\right)_{a \cdot t}=\sum_{n=0}^{n} \frac{(\alpha \cdot t)^{n}}{n !} \cdot e^{-a \cdot t} .
$$

where $\mathrm{P}_{n}=$ relative number of viruses with $n$ lethal hits in a inactivated population after the inactivation time $t . n=$ number of lethal hits per viral genome $(n=0,1,2, \ldots$ etc.). $\alpha=$ apparent constant of inactivation. $t=$ time of inactivation.

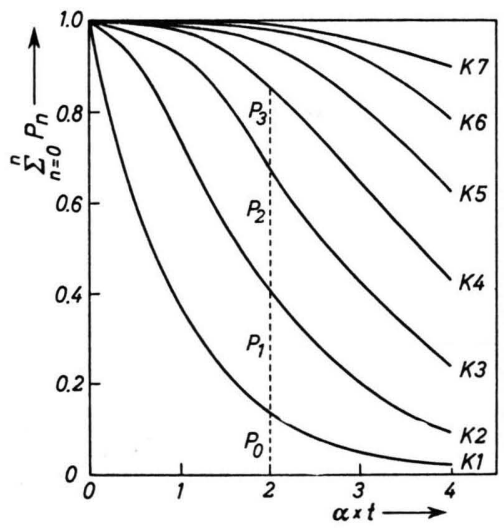

Fig. 5. Graph of the function $\sum_{n=0}^{n}\left(\mathrm{P}_{n}\right)_{\alpha t}=\sum_{n=0}^{n} \frac{(\alpha \cdot t)^{n}}{n !} \cdot e^{-\alpha t}$ (see text). $\mathrm{Kl}$ : relative amount of $\mathrm{P}_{0}$-particles, $\mathrm{K} 2$ : relative amount of $\mathrm{P}_{0}+\mathrm{P}_{1}$-particles, $\mathrm{K} 3$ : relative amount of $\mathrm{P}_{0}+\mathrm{P}_{1}+$ $P_{2}$-particles etc. The relative amount of survival is known from the plaque assay.

The relative amounts of virus particles which received $1,2,3, \ldots$ ore $n$ (up to $n=7$ in Fig. 5) lethal hits can be determined for any degree of inactivation.

For simplicity, we shall refer to $\mathrm{P}_{0}, \mathrm{P}_{1}, \mathrm{P}_{2} \ldots$ etc. particles in the text and in the discussion. $m_{0}$, $m_{1}, m_{2} \ldots$ etc. correspond to the respective multiplicities.

With the above data, condition $c$ is fulfilled. This permits to study the question whether or not virus particles with one lethal hit are still able to contribute to the inhibitory effect on cellular protein synthesis.

\section{Experiments with inactivated virus}

In order to study the participation of $\mathrm{P}_{1}$-particles in the inhibitory effect an experiment was carried

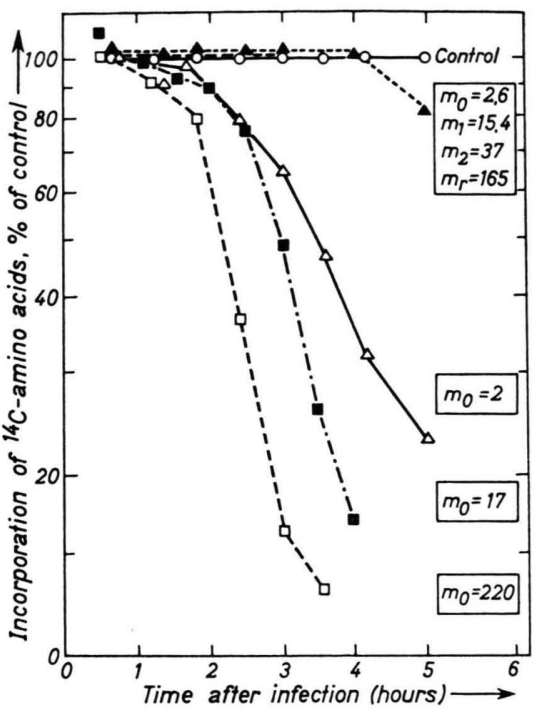

Fig. 6. Inhibition of cellular protein synthesis by a partially $(98,8 \%)$ inactivated poliovirus preparation. $0-0$ uninfected control, $\boldsymbol{\Delta}--\boldsymbol{\Delta}$ infected by inactivated virus $\left(m_{0}=2.6\right.$, $\left.m_{1}=15.4, m_{2}=37, m_{\mathrm{r}}=165\right) . \triangle \longrightarrow \triangle$ infected by untreated virus, $m_{0}=2$, $\square$ infected by untreated virus, $m_{0}=17$, $\square--\square$ infected by untreated virus, $m_{0}=220$.

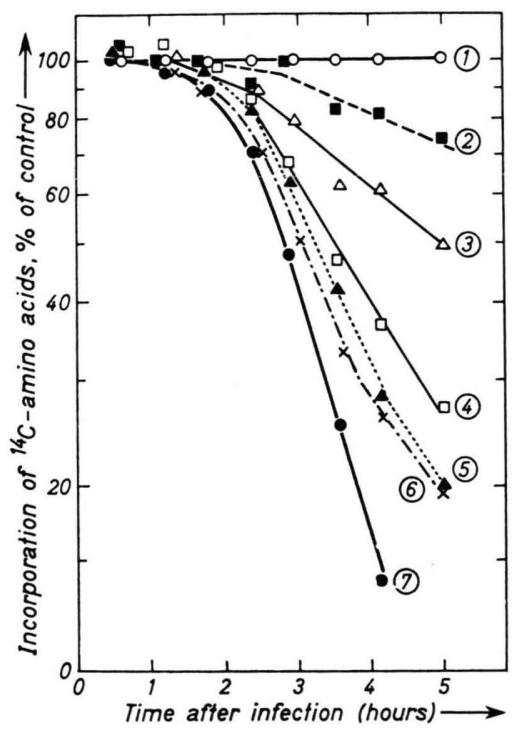

Fig. 7. Inhibition of cellular protein synthesis after infection by artificial mixtures of untreated polioviruses and totally inactivated $(99,996 \%)$ polioviruses. The diagram represents experiments for different ratios of multiplicities:

$$
q=\frac{\text { active virus particles }}{\text { inactive virus particles }}
$$

1. ○— $\mathrm{O} q=0: 100 ; 2$. - $q-q=2: 100 ; 3 . \triangle \longrightarrow \triangle$ $q=1: 0 ; 4 . \square-\square q=2: 0 ; 5 . \Delta \cdots \Delta \mathrm{q}=10: 100$;

20 C. W. Hiatt, Bacteriol. Rev. 28, 150 [1964]. 
out using a preparation of poliovirus previously inactivated by 98.9 percent. Results obtained with this preparation and the appropriate controls are given in Fig. 6.

If $\mathrm{P}_{\mathbf{1}}$-particles participated in the inhibitory action, one would expect the effect of a multiplicity $m_{0}+m_{1}=18$. The Figure shows, however, that the effect is even smaller than that of the corresponding residual infectivity $\left(m_{0}=2.6\right)$. Further experiments reveal a competition between inactivated and infectious particles. This is shown in Fig. 7 which gives the results obtained with artificial mixtures of untreated and fully inactivated virus preparations. When the ratio of active: inactivated virus is smaller than $1: 10$ the competition becomes manifest. When the ratio is bigger, the effect observed (effective multiplicity) is practically that of the multiplicity of active virus alone.

Regarding the results obtained with the partially inactivated $(98.8 \%)$ virus preparation the ratio of active virus $\left(m_{0}=2.6\right)$ to all inactivated viruses $\left(m_{n}=217.4\right)$ is $1: 83.5$. Owing to the competition described above the effective multiplicity is, therefore, not 2.6 but $2.6: 217.4=0.0112$.

If, on the other hand, also $\mathrm{P}_{1}$-particles had contributed to the shut-off phenomenon, the multiplicity were $m_{0}+m_{1}=18$ and the ratio to all other viruses were $1: 202=1: 11$. This ratio is outside the range of strong competition and thus the multiplicity of $m_{0}+m_{1}=18$ were practically equai to an effective multiplicity.

The data in Fig. 6 show that the partially inactivated virus preparation $\left(m_{0}=2.6\right)$ inhibited the cellular protein synthesis much less than either of the corresponding controls $\left(m_{0}=2\right.$ and $\left.m_{0}=17\right)$.

Actually, it behaved similar to the artificial mixture 2 in Fig. $7\left(m_{0}=2, m_{n}=100\right)$ corresponding to an effective multiplicity $=\mathbf{0 . 0 2}$.

One may conclude, therefore, that even virus particles with a single lethal hit no longer participate in the inhibition of cellular protein synthesis.

21 M. F. Jacobson and D. Baltimore, Proc. nat. Acad. Sci. USA 61, 77 [1968].

\section{Discussion}

As demonstrated by the experiments with inactivated poliovirus preparations the fully intact genome is essential for the inhibition of cellular protein synthesis. This partial function of the genome thus is equally sensitive to inactivation as is the total function, e.g. virus infectivity. Both are abrogated by a single lethal hit. This noteworthy result can be accounted for in different ways.

\section{a) Inhibition of translation}

Protein synthesis on the infecting (incoming) viral RNA cannot proceed or is incorrect if the RNA carries a lethal hit. Consequently no or faulty "inhibitory protein (s)" is (are) synthesized.

\section{b) Inhibition of viral RNA replication}

Viral protein synthesis is still possible on the lethally damaged RNA but the latter no longer serves as a template for RNA replication. Accordingly, the amount of viral proteins, including the "inhibitory protein (s)" remains at too low a level to cause measurable effects.

\section{c) Inhibition of cleavage}

The cleavage of a large primary viral protein into functional and structural proteins ${ }^{21,22}$ is inhibited if it is derived from viral RNA carrying lethal hits. The consequence would be the same as discussed in a).

The question, whether or not virus particles with one lethal hit no longer participate in viral-RNA synthesis is the subject of a further investigation described in the following paper.

This work was supported by the Deutsche Forschungsgemeinschaft and the Stiftung Volkswagenwerk. We thank Professor Dr. MAURer, Institute for Medical Radiology, University of Würzburg, for valuable discussions and Mrs. A. KREISEL for technical assistance.

22 D. F. Summers and J. V. Maizel, Proc. nat. Acad. Sci. USA 59, 966 [1968]. 